\title{
An Analytical Formulation for Pollutant Dispersion Simulation in the Atmospheric Boundary Layer
}

\author{
Glênio A. Gonçalves, Regis S. de Quadros, Daniela Buske*
}

Federal University of Pelotas (UFPel), Department of Mathematics and Statistics (IFM/DME), Pelotas, Brazil.

Email: *daniela.buske@ufpel.edu.br

Received June $14^{\text {th }}, 2013$; revised July $16^{\text {th }}, 2013$; accepted August $3^{\text {rd }}, 2013$

Copyright (C) 2013 Glênio A. Gonçalves et al. This is an open access article distributed under the Creative Commons Attribution License, which permits unrestricted use, distribution, and reproduction in any medium, provided the original work is properly cited.

\begin{abstract}
In this work we present the solution of the two-dimensional advection-diffusion equation by the GILTT method. The GILTT approach uses, in the series expansion, eigenfunctions given in terms of cosine functions. Here, a different expansion for the solution of the advection-diffusion equation will be explored. In other words, a Sturm-Liouville problem carrying more information of the original problem is considered, given by Bessel functions. Numerical simulations and comparisons with experimental data are presented.
\end{abstract}

Keywords: Analytical Solution; Advection-Diffusion Equation; Air Pollution Modeling; Integral Transform; Bessel Functions

\section{Introduction}

The advection-diffusion equation has long been used to describe the dispersion of contaminants in the atmosphere [1]. Efforts have been made over the years to obtain analytical solutions of this equation in order to modeling air pollution. According to [2,3], these solutions are valid for very specialized practical situations, and in majority with restrictions on wind and eddy diffusivities vertical profiles [4-18]. To solve the advection-diffusion equation for more realistic physical scenario appeared in the literature the ADMM (Advection Diffusion Multilayer Method) approach $[19,20]$, valid for any eddy diffusivity and wind profile depending on the height. The main idea relies on the discretization of the Atmospheric Boundary Layer (ABL) in a multilayer domain, assuming in each layer that the eddy diffusivity and wind profile take averaged values. The resulting advection-diffusion equation in each layer is then solved by the Laplace Transform technique. A more general methodology, which skips the multilayer discretisation of the height $z$ appearing in the ADMM approach, is known in the literature as GILTT (Generalized Integral Laplace Transform Technique) approach $[2,3,21]$. The main idea of this methodology relies on the expansion of the pollutant concentration in series of eigenfunctions attained from an auxiliary Sturm-Liouville problem, replacement of this equation in

"Corresponding author. the advection-diffusion equation and taking moments. The procedure results a matrix ordinary differential equation which is solved analytically by the Laplace Transform technique. Similar solutions were proposed by [22, 23].

To reach our objective, we begin presenting the solution of the two-dimensional advection-diffusion equation in Cartesian geometry by the GILTT approach [2], considering that the eddy diffusivity and the vertical wind profile depend on the $z$ variable. Traditionally, the GILTT approach uses as basis eigenfunctions given in terms of cosine functions. Here, another Sturm-Liouville problem will be considered, carrying more information of the original problem. In this case, the eigenfunctions are given by Bessel functions. Once we construct the general solution, numerical simulations and future perspectives of this methodology are presented.

\section{The Advection-Diffusion Equation and the GILTT Method}

For a Cartesian coordinate system the advection-diffusion equation, using first order closure of turbulence, is written like [24]:

$$
\begin{aligned}
& \frac{\partial \bar{c}}{\partial t}+\bar{u} \frac{\partial \bar{c}}{\partial x}+\bar{v} \frac{\partial \bar{c}}{\partial y}+\bar{w} \frac{\partial \bar{c}}{\partial z} \\
& =\frac{\partial}{\partial x}\left(K_{x} \frac{\partial \bar{c}}{\partial x}\right)+\frac{\partial}{\partial y}\left(K_{y} \frac{\partial \bar{c}}{\partial y}\right)+\frac{\partial}{\partial z}\left(K_{z} \frac{\partial \bar{c}}{\partial z}\right)+S
\end{aligned}
$$


where $\bar{c}$ denotes the average concentration of a passive $\left(\mathrm{g} / \mathrm{m}^{3}\right), \bar{u}, \bar{v}, \bar{w}$ are the mean wind $(\mathrm{m} / \mathrm{s})$ components along the axis $x, y$ and $z$, respectively and $S$ is the source term. $K_{x}, K_{y}, K_{z}$ are the Cartesian components of eddy diffusivity $\left(\mathrm{m}^{2} / \mathrm{s}\right)$ in the $x, y$ and $z$ directions, respectively. In the first order closure all the information on the turbulence complexity is contained in the eddy diffusivities.

Problem (1) is solved analytically by the 3D-GILTT method $[3,21,25]$. Here, for comparison with experimental data we will assume for the advection-diffusion Equation (1): stationary conditions, crosswind integrated concentrations and that the advection is much higher than the diffusion in the $\mathrm{x}$-direction. After the simplifications, let us consider the problem:

$$
\bar{u} \frac{\partial \bar{c}_{y}}{\partial x}=\frac{\partial}{\partial z}\left(K_{z} \frac{\partial \bar{c}_{y}}{\partial z}\right)
$$

for $0<z<h$ and $x>0$, subject to the boundary conditions of zero flux at the ground and ABL top and a source with emission $Q$ at height $H_{s}\left(\overline{u c}_{y}(0, z)=Q \delta\left(z-H_{s}\right)\right.$ at $\mathrm{x}=0$ ). Here $\bar{c}_{y}$ represents the crosswind integrated concentration, $h$ is the ABL height, $K_{z}$ is the eddy diffusivity variable with the height $z\left(K_{z}=K(z)\right), \bar{u}$ is the longitudinal wind speed $(\bar{u}=\bar{u}(z))$, and $\delta$ is the Dirac delta function.

Problem (2) has a well-known solution by the GILTT method. Following the works of $[2,25]$ we write the solution of problem (2) as:

$$
\bar{c}_{y}(x, z)=\sum_{n=0}^{N} \bar{c}_{n}(x) \Psi_{n}(z)
$$

where $\Psi_{n}(z)$ are the eigenfunctions of an associated Sturm-Liouville problem and $\bar{c}_{n}(x)$ is the transformed concentration.

Traditionally, in the application of the GILTT method, the following auxiliary Sturm-Liouville problem is chosen:

$$
\begin{gathered}
\Psi_{n}^{\prime \prime}(z)+\lambda_{n}^{2} \Psi_{n}(z)=0 \text { at } 0<z<h \\
\Psi_{n}^{\prime}(z)=0 \text { at } z=0, h,
\end{gathered}
$$

which has the solution $\Psi_{n}(z)=\cos \left(\lambda_{n} z\right)$, where $\Psi_{n}(z)$ are the eigenfunctions and $\lambda_{n}=n \pi / h \quad(n=0,1,2, \cdots)$ are the respective eigenvalues.

Here, a different expansion for the solution of the advection-diffusion equation will be explored. In other words, we propose another Sturm-Liouville problem as the basis generator. The idea of this proposal comes from the fact that the auxiliary problem (4) has the same shape of the ordinary differential equation (relative do $z$ variable) that appears in the solution of Equation (2) by the method of separation of variables, when the vertical eddy diffusivity is considered constant. This suggests the possibility of using an auxiliary problem that appears in the solution of Equation (2) by the method of separation of variables, considering linear vertical eddy diffusivity, $K_{z}=z$, given by:

$$
\begin{gathered}
\Psi_{n}^{\prime}\left(z \Psi_{n}^{\prime}(z)\right)+\lambda_{n}^{2} \Psi_{n}(z)=0 \text { at } 0<z<h \\
\Psi_{n}^{\prime}(z)=0 \text { at } z=0, h
\end{gathered}
$$

which has Bessel functions of first specie and order zero as solution $\Psi_{n}(z)=J_{0}\left(\lambda_{n} \sqrt{z / h}\right)$, where $\lambda_{n}$ $(n=0,1,2, \cdots)$ are the positive roots of the Bessel function of first specie and order one, $J_{1}$. Problem (5) carries more information from the original problem than the previous one.

To determine the unknown coefficient $\bar{c}_{n}(x)$ we replace Equation (3) in Equation (1). Applying the integral operator $\int_{0}^{h}(.) \Psi_{m}(z) \mathrm{d} z$, we come out with the result:

$$
\sum_{n=0}^{N} \bar{c}_{n}(x) \int_{0}^{h} u \Psi_{n} \Psi_{m} \mathrm{~d} z-\sum_{n=0}^{N} \bar{c}_{n}(x) \int_{0}^{h} \Psi_{m} \frac{\partial}{\partial z}\left(K_{z} \frac{\partial \Psi_{n}}{\partial z}\right) \mathrm{d} z=0
$$

Using the integration parts technique, we can recast the second integral in Equation (6) as:

$\int_{0}^{h} \Psi_{m} \frac{\partial}{\partial z}\left(K_{z} \frac{\partial \Psi_{n}}{\partial z}\right) \mathrm{d} z=\Psi_{m} K_{z} \frac{\partial \Psi_{n}^{\prime}}{\partial z}-\int_{0}^{h} \Psi_{m}^{\prime} K_{z} \frac{\partial \Psi_{n}^{\prime}}{\partial z} \mathrm{~d} z$ (6a) and once $\Psi_{m} K_{z} \frac{\partial \Psi_{n}^{\prime}}{\partial z}=0$, the Equation (6) is rewritten as:

$$
\sum_{n=0}^{N} \bar{c}_{n}^{\prime}(x) \int_{0}^{h} u \Psi_{n} \Psi_{m} \mathrm{~d} z+\sum_{n=0}^{N} \bar{c}_{n}(x) \int_{0}^{h} \Psi_{m}^{\prime} K_{z} \frac{\partial \Psi_{n}^{\prime}}{\partial z} \mathrm{~d} z=0
$$

which in matrix form reads like:

$$
\boldsymbol{Y}^{\prime}(\boldsymbol{x})+F Y(x)=0
$$

Here $\boldsymbol{Y}^{\prime}(\boldsymbol{x})$ is the vector whose components are $\bar{c}_{n}(x)$ and $F=B^{-1} . E ; \quad B=\left\{b_{n, m}\right\}$ and $E=\left\{e_{n, m}\right\}$ are the matrices whose entries are, respectively:

$$
b_{n, m}=\int_{0}^{h} \bar{u} \Psi_{n} \Psi_{m} \mathrm{~d} z \text { and } e_{n, m}=\int_{0}^{h} \Psi_{m}^{\prime} K_{z} \frac{\mathrm{d} \Psi_{n}^{\prime}}{\mathrm{d} z} \mathrm{~d} z
$$

Equation (8) is subject to the initial condition $\mathrm{Y}(0)$, which is obtained from the source condition $\left(\overline{u c}_{y}(0, z)=Q \delta\left(z-H_{s}\right)\right.$ at $\left.x=0\right)$ by a similar procedure leading to $Y(0)=\bar{c}_{n}(0)=Q \Psi_{m}\left(H_{s}\right) B^{-1}, B^{-1}$ being the inverse of matrix $B$.

The transformed problem represented by the Equation (8) is solved analytically following the work [2], by the combined Laplace transform technique and diagonalization of the matrix $F\left(F=X D X^{-1}\right)$. By this procedure we come out with the result:

$$
Y(x)=X G(x) X^{-1} Y(0),
$$


where $G(x)$ is the diagonal matrix with elements $\mathrm{e}^{-d_{i} x}$, $D$ is the diagonal matrix of eigenvalues $d_{n}$ of the matrix $F, X$ is the matrix of the respective eigenfunctions and $X^{-1}$ it is the inverse.

Therefore, the solution for the concentration given by Equation (3) is now well determined once the vector $\overline{\boldsymbol{c}}_{\boldsymbol{n}}(\boldsymbol{x})$ is known and given by Equation (9).

The solution of the problem (2) using in the series expansion (3) eigenfunctions given in terms of cosine and Bessel functions will be called here as GILTTC and GILTTB, respectively.

\section{Numerical Results}

The performance of the discussed solution was evaluated against experimental ground-level concentration using different dispersion experiments available in the literature. Below we briefly discuss the Copenhagen, PrairieGrass and Hanford dispersion experiments, which allow us to validate the results encountered by the mentioned solutions.

The Copenhagen field campaign took place in the suburbs of Copenhagen in 1978, and is described by [26]. It consisted of tracer released without buoyancy from a tower at a height of $115 \mathrm{~m}$, and collection of tracer sampling units at the ground-level positions at the maximum of three crosswind arcs. The sampling units were positioned at two to six kilometers from the point of release. The site was mainly residential with a roughness length of the $0.6 \mathrm{~m}$. The meteorological conditions during the dispersion experiments ranged from moderately unstable to convective. Table 1 shows a summary of meteorological conditions during the Copenhagen experiments.

In the Prairie-Grass experiment, according [27], the tracer $\mathrm{SO}_{2}$ was released without buoyancy at a height of $0.46 \mathrm{~m}$, and collected at a height of $1.5 \mathrm{~m}$ at five downwind distances (50,100, 200, 400 and $800 \mathrm{~m})$ at O'Neill,

Table 1. The meteorological data observed during the Copenhagen experiment.

\begin{tabular}{cccccc}
\hline Exp. & $\begin{array}{c}\bar{u}(10 \mathrm{~m}) \\
\left(\mathrm{ms}^{-1}\right)\end{array}$ & $u *\left(\mathrm{~ms}^{-1}\right)$ & $L(\mathrm{~m})$ & $w *\left(\mathrm{~ms}^{-1}\right)$ & $h(\mathrm{~m})$ \\
\hline 1 & 3.4 & 0.36 & -37 & 1.8 & 1980 \\
2 & 10.6 & 0.73 & -292 & 1.8 & 1920 \\
3 & 5.0 & 0.38 & -71 & 1.3 & 1120 \\
4 & 4.6 & 0.38 & -133 & 0.7 & 390 \\
5 & 6.7 & 0.45 & -444 & 0.7 & 820 \\
6 & 13.2 & 1.05 & -432 & 2.0 & 1300 \\
7 & 7.6 & 0.64 & -104 & 2.2 & 1850 \\
8 & 9.4 & 0.69 & -56 & 2.2 & 810 \\
9 & 10.5 & 0.75 & -289 & 1.9 & 2090 \\
\hline
\end{tabular}

Nebraska in 1956. The Prairie Grass site was quite flat and much smooth with a roughness length of $0.6 \mathrm{~cm}$. Here we consider the experimental data appearing in the paper [28]. Table 2 summaries the meteorological conditions during the Prairie-Grass experiments.

The Hanford diffusion experiment was conducted in May-June, 1983, on a semi-arid region of south eastern Washington on generally flat terrain. The detailed description of the experiment was provided by [29]. Data were obtained from six dual-tracer releases located at $100,200,800,1600$ and $3200 \mathrm{~m}$ from the source during moderately stable to near-neutral conditions. The release height of $\mathrm{SF}_{6}$ was $2 \mathrm{~m}$ and average release rate was around $0.3 \mathrm{~g} / \mathrm{s}$. The pollutant was collected at a height of $1.5 \mathrm{~m}$. The terrain was considered as an urban terrain with roughness length of $3 \mathrm{~cm}$. The values of ABL parameters are given in Table 3 .

The choice of the turbulent parameterization represents a fundamental aspect for pollutant dispersion modeling. In terms of the convective scaling parameters, the

Table 2. The meteorological data observed during the Prairie-Grass experiment.

\begin{tabular}{|c|c|c|c|c|c|}
\hline Exp. & $L(\mathrm{~m})$ & $h(\mathrm{~m})$ & $w *\left(\mathrm{~ms}^{-1}\right)$ & $\begin{array}{c}\bar{u} \\
(10 \mathrm{~m}) \\
\left(\mathrm{ms}^{-1}\right)\end{array}$ & $Q\left(\mathrm{gs}^{-1}\right)$ \\
\hline 1 & -9 & 260 & 0.84 & 3.2 & 82 \\
\hline 5 & -28 & 780 & 1.64 & 7.0 & 78 \\
\hline 7 & -10 & 1340 & 2.27 & 5.1 & 90 \\
\hline 8 & -18 & 1380 & 1.87 & 5.4 & 91 \\
\hline 9 & -31 & 550 & 1.70 & 8.4 & 92 \\
\hline 10 & -11 & 950 & 2.01 & 5.4 & 92 \\
\hline 15 & -8 & 80 & 0.70 & 3.8 & 96 \\
\hline 16 & -5 & 1060 & 2.03 & 3.6 & 93 \\
\hline 19 & -28 & 650 & 1.58 & 7.2 & 102 \\
\hline 20 & -62 & 710 & 1.92 & 11.3 & 102 \\
\hline 25 & -6 & 650 & 1.35 & 3.2 & 104 \\
\hline 26 & -32 & 900 & 1.86 & 7.8 & 98 \\
\hline 27 & -30 & 1280 & 2.08 & 7.6 & 99 \\
\hline 30 & -39 & 1560 & 2.23 & 8.5 & 98 \\
\hline 43 & -16 & 600 & 1.66 & 6.1 & 99 \\
\hline 44 & -25 & 1450 & 2.20 & 7.2 & 101 \\
\hline 49 & -28 & 550 & 1.73 & 8.0 & 102 \\
\hline 50 & -26 & 750 & 1.91 & 8.0 & 103 \\
\hline 51 & -40 & 1880 & 2.30 & 8.0 & 102 \\
\hline 61 & -38 & 450 & 1.65 & 9.3 & 102 \\
\hline
\end{tabular}


Table 3. The meteorological data observed during the Hanford experiment.

\begin{tabular}{ccccc}
\hline Exp. & $\begin{array}{c}\bar{u}(2 \mathrm{~m}) \\
\left(\mathrm{ms}^{-1}\right)\end{array}$ & $u_{*}\left(\mathrm{~ms}^{-1}\right)$ & $L(\mathrm{~m})$ & $h(\mathrm{~m})$ \\
\hline 1 & 3.63 & 0.40 & 166 & 325 \\
2 & 1.42 & 0.26 & 44 & 135 \\
3 & 2.02 & 0.27 & 77 & 182 \\
4 & 1.50 & 0.20 & 34 & 104 \\
5 & 1.41 & 0.26 & 59 & 157 \\
6 & 1.54 & 0.30 & 71 & 185 \\
\hline
\end{tabular}

vertical eddy diffusivity can be formulated as [30]:

$$
\frac{K_{z}}{w_{*} h}=0.22\left(\frac{z}{h}\right)^{1 / 3}\left(1-\frac{z}{h}\right)^{1 / 3}\left[1-\mathrm{e}^{\left(-\frac{4 z}{h}\right)}-0.0003 \mathrm{e}^{\left(\frac{8 z}{h}\right)}\right]
$$

while for stable conditions [31]:

$$
K_{z}=\frac{0.3(1-z / h) u_{*} z}{1+3.7 z / \Lambda}
$$

where $z$ is height; $h$ is the thickness of the ABL; $w_{*}$ is the convective velocity scale; $\Lambda=L(1-z / h)^{5 / 4} ; L$ is the Monin-Obukhov length and $u_{*}$ is the friction velocity.

In our simulations, we use the wind speed profile described by a power law, according [32],

$$
\frac{\bar{u}_{z}}{\bar{u}_{1}}=\left(\frac{z}{z_{1}}\right)^{\alpha}
$$

where $\bar{u}_{z}$ and $\bar{u}_{1}$ are the mean wind velocity respectively at the heights $z$ and $z_{1}$, while $\alpha$ is an exponent that is related to the intensity of turbulence [33]. For the Copenhagen experiment $\alpha=0.1$ and for the PrairieGrass experiment $\alpha=0.07$.

In Tables 4-6, we present some performances evaluations of the model for the Copenhagen and Prairie-Grass experiments, respectively, using the statistical evaluation procedure described by [34] and defined as:

NMSE (normalized mean square error)

$$
=\overline{\left(C_{o}-C_{p}\right)^{2}} / \overline{C_{p}} \overline{C_{o}} \text {, }
$$

FA2 $=$ fraction of data $(\%$, normalized to 1$)$ for

$$
0.5 \leq\left(C_{p} / C_{o}\right) \leq 2,
$$

COR (correlation coefficient)

$$
=\overline{\left(C_{o}-\overline{C_{o}}\right)\left(C_{p}-\overline{C_{p}}\right)} / \sigma_{o} \sigma_{p},
$$

$\mathrm{FB}($ fractional bias $)=\overline{C_{o}}-\overline{C_{p}} / 0.5\left(\overline{C_{o}}+\overline{C_{p}}\right)$,

$$
\begin{aligned}
& \text { FS ( fractional standard deviations) } \\
& =\left(\sigma_{o}-\sigma_{p}\right) / 0.5\left(\sigma_{o}+\sigma_{p}\right)
\end{aligned}
$$

where the subscripts $o$ and $p$ refer to observed and predicted quantities, respectively, and the over bar indicates an averaged value. The statistical index NMSE represents the model values dispersion in respect to data dispersion. The statistical index FB says if the predicted quantities underestimate or overestimate the observed ones. The best results are expected to have values near to zero for the indices NMSE, FB and FS, and near to 1 in the indices COR and FA2.

For the Copenhagen experiment the statistical indices of Table 4 point out that a good agreement is obtained between experimental data and the GILTT method for both cosine and Bessel basis, regarding the NMSE, FB and FS values relatively near to zero and COR relatively near to 1 . At this point, we can affirm that no significant difference between the models was observed for the high source of the Copenhagen experiment.

Table 5 shows the performance of the solution for the Prairie-Grass experiment. The statistical indices of the table point out that a reasonable agreement is obtained between experimental data and the GILTT method. It is important to notice that the GILTTB numerically converges faster than GILTTC (while GILTTB needs 100 eigenvalues, GILTTC needs 300 eigenvalues to reach a

Table 4. Statistical indices evaluating the model performance using the Copenhagen experiment.

\begin{tabular}{cccccc}
\hline Model & NMSE & COR & FA2 & FB & FS \\
\hline GILTTC N =100 & 0.05 & 0.91 & 1.00 & -0.01 & 0.14 \\
GILTTB N = 100 & 0.05 & 0.91 & 1.00 & -0.04 & 0.13 \\
\hline
\end{tabular}

Table 5. Statistical indices evaluating the model performance using the Prairie-Grass experiment.

\begin{tabular}{cccccc}
\hline Model & NMSE & COR & FA2 & FB & FS \\
\hline GILTTC N = 100 & 0.80 & 0.83 & 0.64 & 0.39 & 0.56 \\
GILTTC N = 200 & 0.23 & 0.92 & 0.71 & 0.06 & 0.33 \\
GILTTC N = 300 & 0.15 & 0.95 & 0.72 & -0.01 & 0.28 \\
GILTTB N = 100 & 0.11 & 0.97 & 0.71 & -0.1 & 0.23 \\
\hline
\end{tabular}

Table 6. Statistical indices evaluating the model performance using the Hanford experiment.

\begin{tabular}{cccccc}
\hline Model & NMSE & COR & FA2 & FB & FS \\
\hline GILTTC N $=30$ & 0.21 & 0.91 & 0.83 & -0.16 & -0.01 \\
GILTTC N $=60$ & 0.23 & 0.91 & 0.80 & -0.20 & -0.03 \\
GILTTB N $=30$ & 0.24 & 0.91 & 0.77 & -0.20 & -0.03 \\
\hline
\end{tabular}


similar numerical result).

For the Hanford experiment were used the eddy diffusivity Equation (14) and power wind profile Equation (15) with $\alpha=0.6$. The statistical indices of Table 6 point out that a good agreement is obtained between experimental data and models. Again, the GILTTC need more eigenvalues to reach a similar numerical result obtained with the GILTTB.

In the following are presented in Tables 7-9 the numerical comparisons of the GILTT method results against the experimental data of Copenhagen, Prairie-Grass and Hanford experiments.

Furthermore, Figures 1-3 show the observed and predicted scatter diagram of crosswind ground-level concentrations for the three experiments considered in this work. In the graphics the symbol represents the GILTTC,

Table 7. Observed and predicted crosswind-integrated concentrations $\mathrm{C} / \mathrm{Q}\left(10^{-4} \mathrm{sm}^{-2}\right)$ at the Copenhagen experiment.

\begin{tabular}{|c|c|c|c|c|}
\hline Run & $\begin{array}{c}\text { Distance } \\
(\mathrm{m})\end{array}$ & $\begin{array}{c}\text { OBS } \\
\left(10^{-4} \mathrm{sm}^{-2}\right)\end{array}$ & $\begin{array}{c}\text { GILTTC } \\
\left(10^{-4} \mathrm{sm}^{-2}\right)\end{array}$ & $\begin{array}{l}\text { GILTTB } \\
\left(10^{-4} \mathrm{sm}^{-2}\right)\end{array}$ \\
\hline 1 & 1900 & 6.48 & 6.86 & 7.27 \\
\hline 1 & 3700 & 2.31 & 3.98 & 4.11 \\
\hline 2 & 2100 & 5.38 & 4.64 & 4.87 \\
\hline 2 & 4200 & 2.95 & 3.06 & 3.24 \\
\hline 3 & 1900 & 8.20 & 8.15 & 8.45 \\
\hline 3 & 3700 & 6.22 & 5.20 & 5.32 \\
\hline 3 & 5400 & 4.30 & 3.99 & 4.05 \\
\hline 4 & 4000 & 11.66 & 9.25 & 9.30 \\
\hline 5 & 2100 & 6.72 & 8.54 & 8.53 \\
\hline 5 & 4200 & 5.84 & 6.73 & 6.90 \\
\hline 5 & 6100 & 4.97 & 5.40 & 5.51 \\
\hline 6 & 2000 & 3.96 & 3.50 & 3.52 \\
\hline 6 & 4200 & 2.22 & 2.51 & 2.62 \\
\hline 6 & 5900 & 1.83 & 1.98 & 2.05 \\
\hline 7 & 2000 & 6.70 & 4.67 & 4.97 \\
\hline 7 & 4100 & 3.25 & 2.76 & 2.88 \\
\hline 7 & 5300 & 2.23 & 2.24 & 2.31 \\
\hline 8 & 1900 & 4.16 & 4.84 & 4.96 \\
\hline 8 & 3600 & 2.02 & 3.28 & 3.33 \\
\hline 8 & 5300 & 1.52 & 2.63 & 2.65 \\
\hline 9 & 2100 & 4.58 & 4.44 & 4.67 \\
\hline 9 & 4200 & 3.11 & 2.92 & 3.11 \\
\hline 9 & 6000 & 2.59 & 2.20 & 2.31 \\
\hline
\end{tabular}

Table 8. Ground-level crosswind integrated concentrations $\left(\mathrm{gm}^{-2}\right)$ measured during the Prairie Grass experiment (first line) and simulated by the GILTTC and GILTTB methods (second and third lines, respectively).

\begin{tabular}{|c|c|c|c|c|c|}
\hline Run No. & $\begin{array}{c}50 \mathrm{~m} \\
\left(\mathrm{gm}^{-2}\right)\end{array}$ & $\begin{array}{l}100 \mathrm{~m} \\
\left(\mathrm{gm}^{-2}\right)\end{array}$ & $\begin{array}{l}200 \mathrm{~m} \\
\left(\mathrm{gm}^{-2}\right)\end{array}$ & $\begin{array}{l}400 \mathrm{~m} \\
\left(\mathrm{gm}^{-2}\right)\end{array}$ & $\begin{array}{l}800 \mathrm{~m} \\
\left(\mathrm{gm}^{-2}\right)\end{array}$ \\
\hline \multirow{3}{*}{1} & 7.00 & 2.30 & 0.51 & 0.16 & 0.06 \\
\hline & 5.73 & 3.67 & 1.93 & 0.90 & 0.41 \\
\hline & 5.62 & 3.62 & 1.93 & 0.90 & 0.41 \\
\hline \multirow{3}{*}{5} & 3.30 & 1.80 & 0.81 & 0.29 & 0.09 \\
\hline & 3.07 & 2.07 & 1.21 & 0.61 & 0.27 \\
\hline & 2.99 & 2.17 & 1.30 & 0.66 & 0.29 \\
\hline \multirow{3}{*}{7} & 4.00 & 2.20 & 1.00 & 0.40 & 0.18 \\
\hline & 3.02 & 1.93 & 1.07 & 0.52 & 0.23 \\
\hline & 4.12 & 2.47 & 1.28 & 0.59 & 0.25 \\
\hline \multirow{3}{*}{8} & 5.10 & 2.60 & 1.10 & 0.19 & 0.14 \\
\hline & 3.25 & 2.19 & 1.29 & 0.66 & 0.30 \\
\hline & 4.46 & 2.92 & 1.59 & 0.77 & 0.33 \\
\hline \multirow{3}{*}{9} & 3.70 & 2.20 & 1.00 & 0.41 & 0.13 \\
\hline & 3.27 & 2.24 & 1.30 & 0.65 & 0.29 \\
\hline & 2.90 & 2.17 & 1.33 & 0.67 & 0.30 \\
\hline \multirow{3}{*}{10} & 4.50 & 1.90 & 0.71 & 0.20 & 0.03 \\
\hline & 3.56 & 2.23 & 1.21 & 0.58 & 0.25 \\
\hline & 4.08 & 2.51 & 1.33 & 0.62 & 0.26 \\
\hline \multirow{3}{*}{15} & 7.10 & 3.40 & 1.35 & 0.37 & 0.11 \\
\hline & 5.60 & 3.66 & 2.01 & 1.02 & 0.53 \\
\hline & 5.59 & 3.66 & 2.01 & 1.02 & 0.53 \\
\hline \multirow{3}{*}{16} & 5.00 & 1.80 & 0.48 & 0.10 & 0.02 \\
\hline & 4.08 & 2.39 & 1.22 & 0.55 & 0.23 \\
\hline & 4.93 & 2.73 & 1.34 & 0.59 & 0.24 \\
\hline \multirow{3}{*}{19} & 4.50 & 2.20 & 0.86 & 0.27 & 0.06 \\
\hline & 4.09 & 2.77 & 1.60 & 0.80 & 0.36 \\
\hline & 3.74 & 2.79 & 1.70 & 0.85 & 0.37 \\
\hline \multirow{3}{*}{20} & 3.40 & 1.80 & 0.85 & 0.34 & 0.13 \\
\hline & 2.89 & 2.07 & 1.28 & 0.68 & 0.32 \\
\hline & 2.55 & 2.05 & 1.35 & 0.73 & 0.33 \\
\hline \multirow{3}{*}{25} & 7.90 & 2.70 & 0.75 & 0.30 & 0.06 \\
\hline & 6.52 & 3.80 & 1.91 & 0.86 & 0.37 \\
\hline & 6.54 & 4.02 & 2.04 & 0.89 & 0.37 \\
\hline \multirow{3}{*}{26} & 3.90 & 2.20 & 1.04 & 0.39 & 0.13 \\
\hline & 3.33 & 2.28 & 1.35 & 0.69 & 0.31 \\
\hline & 3.57 & 2.53 & 1.48 & 0.75 & 0.33 \\
\hline \multirow{3}{*}{27} & 4.30 & 2.30 & 1.16 & 0.46 & 0.18 \\
\hline & 2.88 & 2.01 & 1.22 & 0.65 & 0.30 \\
\hline & 3.80 & 2.66 & 1.50 & 0.75 & 0.33 \\
\hline \multirow{3}{*}{30} & 4.20 & 2.30 & 1.11 & 0.40 & 0.10 \\
\hline & 2.37 & 1.71 & 1.09 & 0.60 & 0.29 \\
\hline & 3.27 & 2.46 & 1.46 & 0.75 & 0.34 \\
\hline \multirow{3}{*}{43} & 5.00 & 2.40 & 1.09 & 0.37 & 0.12 \\
\hline & 4.22 & 2.70 & 1.48 & 0.70 & 0.31 \\
\hline & 3.95 & 2.75 & 1.56 & 0.74 & 0.31 \\
\hline \multirow{3}{*}{44} & 4.50 & 2.30 & 1.09 & 0.43 & 0.14 \\
\hline & 2.80 & 1.95 & 1.19 & 0.63 & 0.29 \\
\hline & 3.87 & 2.68 & 1.51 & 0.75 & 0.33 \\
\hline \multirow{3}{*}{49} & 4.30 & 2.40 & 1.16 & 0.45 & 0.15 \\
\hline & 3.69 & 2.49 & 1.42 & 0.70 & 0.31 \\
\hline & 3.31 & 2.44 & 1.47 & 0.73 & 0.32 \\
\hline
\end{tabular}




\section{Continued}

\begin{tabular}{llllll}
50 & 4.20 & 2.30 & 0.91 & 0.39 & 0.11 \\
& 3.53 & 2.37 & 1.37 & 0.68 & 0.31 \\
& 3.39 & 2.46 & 1.47 & 0.73 & 0.32 \\
& & & \\
5 & 4.70 & 2.40 & 1.00 & 0.38 & 0.08 \\
& 2.28 & 1.67 & 1.08 & 0.61 & 0.30 \\
& 3.61 & 2.68 & 1.60 & 0.83 & 0.37 \\
& 3.50 & 2.10 & 1.14 & 0.53 & 0.20 \\
61 & 3.33 & 2.37 & 1.40 & 0.71 & 0.32 \\
& 3.00 & 2.25 & 1.39 & 0.72 & 0.32 \\
\hline
\end{tabular}

Table 9. Observed and predicted crosswind-integrated concentrations $\mathrm{C} / \mathrm{Q}\left(10^{-3} \mathrm{sm}^{-2}\right)$ at Hanford experiment.

\begin{tabular}{|c|c|c|c|c|}
\hline Run No. & $\begin{array}{l}\text { Distance } \\
\quad(\mathrm{m})\end{array}$ & $\begin{array}{c}\mathrm{OBS} \\
\left(10^{-3} \mathrm{sm}^{-2}\right)\end{array}$ & $\begin{array}{c}\text { GILTTC } \\
\left(10^{-3} \mathrm{sm}^{-2}\right)\end{array}$ & $\begin{array}{c}\text { GILTTB } \\
\left(10^{-3} \mathrm{sm}^{-2}\right)\end{array}$ \\
\hline 1 & 100 & 19.5 & 36.28 & 38.92 \\
\hline 1 & 200 & 11.7 & 22.86 & 23.65 \\
\hline 1 & 800 & 3.7 & 7.43 & 7.48 \\
\hline 1 & 1600 & 2.1 & 4.14 & 4.15 \\
\hline 1 & 3200 & 1.3 & 2.34 & 2.34 \\
\hline 2 & 100 & 51.9 & 82.08 & 81.74 \\
\hline 2 & 200 & 36.7 & 50.11 & 50.02 \\
\hline 2 & 800 & 12.9 & 17.96 & 17.95 \\
\hline 2 & 1600 & 9.1 & 11.00 & 11.00 \\
\hline 2 & 3200 & 7.2 & 6.94 & 6.93 \\
\hline 3 & 100 & 27.1 & 65.82 & 65.49 \\
\hline 3 & 200 & 18.1 & 40.04 & 39.96 \\
\hline 3 & 800 & 5.9 & 13.46 & 13.46 \\
\hline 3 & 1600 & 3.3 & 7.87 & 7.87 \\
\hline 3 & 3200 & 1.8 & 4.73 & 4.73 \\
\hline 4 & 100 & 91.8 & 99.91 & 99.60 \\
\hline 4 & 200 & 48.6 & 63.56 & 63.47 \\
\hline 4 & 800 & 20.1 & 23.70 & 23.69 \\
\hline 4 & 1600 & 13.1 & 14.66 & 14.66 \\
\hline 4 & 3200 & 9.2 & 9.31 & 9.31 \\
\hline 5 & 100 & 83.9 & 78.41 & 78.06 \\
\hline 5 & 200 & 42.4 & 47.09 & 47.00 \\
\hline 5 & 800 & 10.5 & 16.28 & 16.27 \\
\hline 5 & 1600 & 8.6 & 9.79 & 9.79 \\
\hline 5 & 3200 & 6.6 & 6.07 & 6.07 \\
\hline 6 & 100 & 88.4 & 67.05 & 66.86 \\
\hline 6 & 200 & 61.1 & 39.77 & 39.72 \\
\hline 6 & 800 & 13.4 & 13.43 & 13.42 \\
\hline 6 & 1600 & 6.2 & 7.98 & 7.98 \\
\hline 6 & 3200 & 3.1 & 4.89 & 4.89 \\
\hline
\end{tabular}

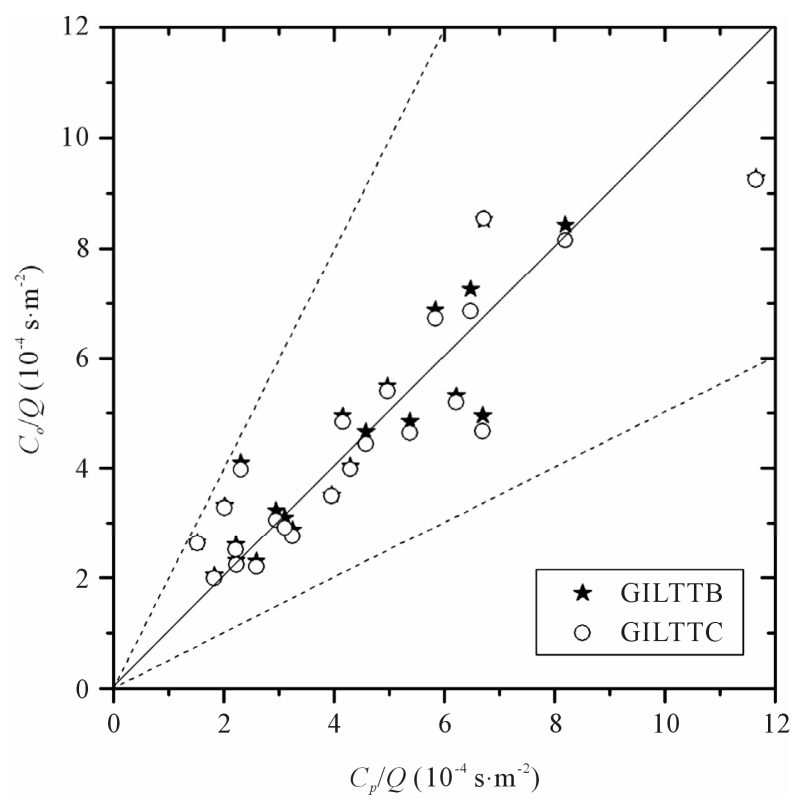

Figure 1. Comparison between observed $\left(C_{o}\right)$ and predicted $\left(C_{p}\right)$ concentrations (normalized by $Q$ ) for the Copenhagen experiment. Lines indicate a factor of two $\left(C_{0} / C_{p} \in[0.5 ; 2]\right)$.

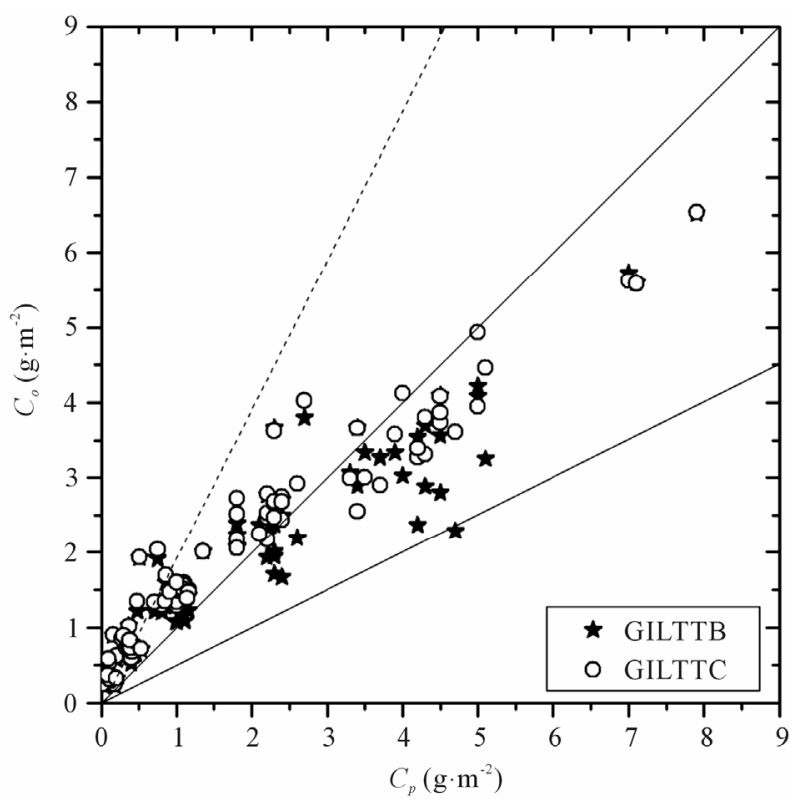

Figure 2. Comparison between observed $\left(C_{o}\right)$ and predicted $\left(C_{p}\right)$ concentrations for the Prairie-Grass experiment. Lines indicate a factor of two $\left(C_{0} / C_{p} \in[0.5 ; 2]\right)$.

and lines the GILTTB solution.

In all the tables and figures, we considered the data numerically converged for both bases. In this respect, it is important to note that the model simulates quite well the observed concentration for all the cases. The greatest difference between the models is seen for the PrairieGrass experiment. 


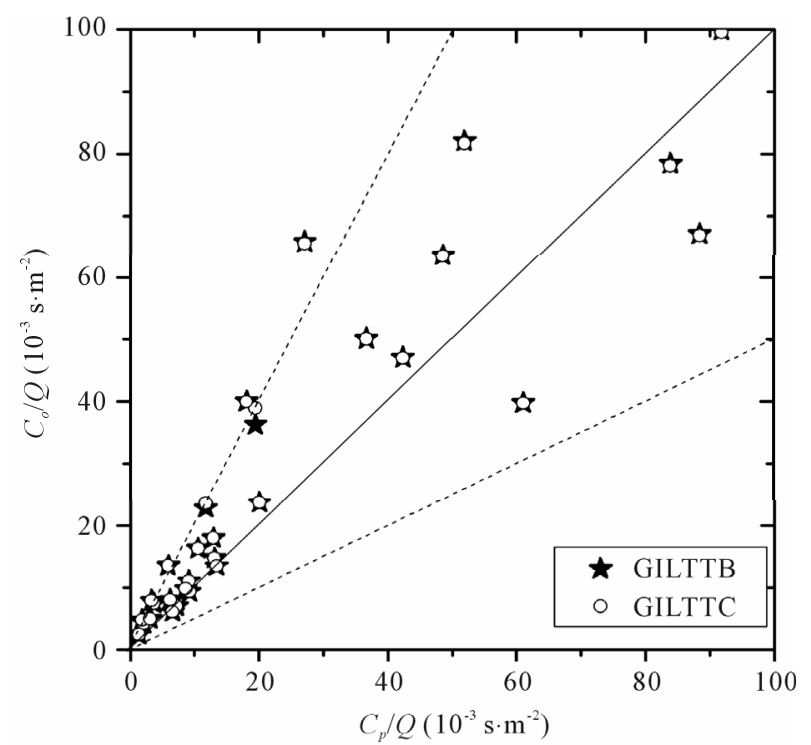

Figure 3. Comparison between observed $\left(C_{o}\right)$ and predicted $\left(C_{p}\right)$ concentrations (normalized by $Q$ ) for the Hanford experiment. Lines indicate a factor of two $\left(C_{0} / C_{p} \in[0.5 ; 2]\right)$.

\section{Conclusions}

Focusing our attention on the pollution dispersion simulation in atmosphere, we present an analytical solution in series expansion given by the well-known GILTT method to solve the two-dimensional advection-diffusion equation by the GILTT approach. A Sturm-Liouville problem carrying more information of the original problem, given by Bessel functions, was considered,

For the problems discussed, we promptly realize the very good results achieved, under statistical point of view, by the GILTT method when compared with the experimental data for both cosine and Bessel basis used. For the case of high source no significant difference was observed between GILTTC and GILTTB. However, for the low source, GILTTB numerically converges faster than GILTTC. We focus our future attention on the direction of the generalization of this solution considering an infinite boundary layer.

\section{Acknowledgements}

The authors thank CNPq (Conselho Nacional de Desenvolvimento Científico e Tecnológico) and FAPERGS (Fundação de Amparo à Pesquisa do Estado do Rio Grande do Sul) for the partial financial support of this work.

\section{REFERENCES}

[1] J. H. Seinfeld and S. N. Pandis, "Atmospheric chemistry and physics," John Wiley \& Sons, New York, 1998.

[2] D. M. Moreira, M. T. Vilhena, D. Buske and T. Tirabassi,
"The State-of-Art of the GILTT Method to Simulate Pollutant Dispersion in the Atmosphere," Atmospheric Research, Vol. 92, No. 1, 2009, pp. 1-17. doi:10.1016/j.atmosres.2008.07.004

[3] D. Buske, M. T. Vilhena, T. Tirabassi and B. Bodmann, "Air Pollution Steady-State Advection Diffusion Equation: The General Three-Dimensional Solution," Journal of Environmental Protection, Vol. 3, No. 2, 2012, pp. 1124-1134. doi:10.4236/jep.2012.329131

[4] W. Rounds, "Solutions of the Two-Dimensional Diffusion Equation," Transactions of American Geophysical Union, Vol. 36, 1955, pp. 395-405. doi:10.1029/TR036i003p00395

[5] F. B. Smith, "The Diffusion of Smoke from a Continuous Elevated Point Source into a Turbulent Atmosphere," Journal of Fluid Mechanics, Vol. 2, No. 1, 1957, pp. 4976. doi:10.1017/S0022112057000737

[6] R. A. Scriven and B. A. Fisher, "The Long Range Transport of Airborne Material and Its Removal by Deposition and Washout-II. The Effect of Turbulent Diffusion," Atmospheric Environment, Vol. 9, No. 1, 1975, pp. 59-69. doi:10.1016/0004-6981(75)90054-2

[7] C. Demuth, "A Contribution to the Analytical Steady Solution of the Diffusion Equation for Line Sources," Atmospheric Environment, Vol. 12, No. 5, 1978, pp. 1255-1258. doi:10.1016/0004-6981(78)90399-2

[8] A. P. van Ulden, "Simple Estimates for Vertical Diffusion from Sources near the Ground," Atmospheric Environment, Vol. 12, No. 11, 1978, pp. 2125-2129. doi:10.1016/0004-6981(78)90167-1

[9] F. T. M. Nieuwstadt, "An Analytical Solution of the Time-Dependent, One-Dimensional Diffusion Equation in the Atmospheric Boundary Layer," Atmospheric Environment, Vol. 14, No. 12, 1980, pp. 1361-1364. doi:10.1016/0004-6981(80)90154-7

[10] F. T. M. Nieuwstadt and B. J. de Haan, "An Analytical Solution of One-Dimensional Diffusion Equation in a Non-Stationary Boundary Layer with an Application to Inversion Rise Fumigation," Atmospheric Environment, Vol. 15, No. 5, 1981, pp. 845-851. doi:10.1016/0004-6981(81)90289-4

[11] M. Tagliazucca, T. Nanni and T. Tirabassi, "An Analytical Dispersion Model for Sources in the Surface Layer," Novembre-Dicembre, Vol. 8, No. 6, 1985, pp. 771-781.

[12] T. Tirabassi, "Analytical Air Pollution and Diffusion Models," Water, Air and Soil Pollution, Vol. 47, No. 1-2, 1989, pp. 19-24. doi:10.1007/BF00468993

[13] W. Koch, "A Solution of the Two-Dimensional Atmospheric Diffusion Equation with Height-Dependent Diffusion-Coefficient Including Ground-Level Absorption," Atmospheric Environment, Vol. 23, No. 8, 1989, pp. 1729-1732. doi:10.1016/0004-6981(89)90057-7

[14] T. Tirabassi and U. Rizza, "Applied Dispersion Modelling for Ground-Level Concentrations from Elevated Sources," Atmospheric Environment, Vol. 28, No. 4, 1994, pp. 611615. doi:10.1016/1352-2310(94)90037-X

[15] M. Sharan, M. P. Singh and A. K. Yadav, "A Mathematical Model for the Atmospheric Dispersion in Low 
Winds with Eddy Diffusivities as Linear Function of Downwind Distance," Atmospheric Environment, Vol. 30, No. 7, 1996, pp. 1137-1145. doi:10.1016/1352-2310(95)00368-1

[16] J. S. Lin and L. M. Hildemann, "A Generalised Mathematical Scheme to Analytically Solve the Atmospheric Diffusion Equation with Dry Deposition," Atmospheric Environment, Vol. 31, No. 1, 1997, pp. 59-71. doi:10.1016/S1352-2310(96)00148-3

[17] M. Sharan and M. Modani, "An Analytical Study for the Dispersion of Pollutants in a Finite Layer under Low Wind Conditions," Pure and Applied Geophysics, Vol. 162, No. 10, 2005, pp. 1861-1892. doi:10.1007/s00024-005-2696-5

[18] M. Sharan and M. Modani, "A Two-Dimensional Analytical Model for the Dispersion of Air-Pollutants in the Atmosphere with a Capping Inversion," Atmospheric Environment, Vol. 40, No. 19, 2006, pp. 3469-3489. doi:10.1016/j.atmosenv.2006.01.051

[19] D. M. Moreira, M. T. Vilhena, T. Tirabassi, C. Costa and B. Bodmann, "Simulation of Pollutant Dispersion in Atmosphere by the Laplace Transform: The ADMM Approach," Water, Air and Soil Pollution, Vol. 177, No. 1-4, 2006, pp. 411-439. doi:10.1007/s11270-006-9182-2

[20] C. P. Costa, M. T. Vilhena, D. M. Moreira and T. Tirabassi, "Semi-Analytical Solution of the Steady ThreeDimensional Advection-Diffusion Equation in the Planetary Boundary Layer," Atmospheric Environment, Vol. 40, No. 29,2006 , pp. $5659-5669$. doi:10.1016/j.atmosenv.2006.04.054

[21] D. Buske, M. T. Vilhena, C. F. Segatto and R. S. Quadros, "A General Analytical Solution of the Advection-Diffusion Equation for Fickian Closure," In: Integral Methods in Science and Engineering: Computational and Analytic Aspects, Birkhäuser, Boston, 2011, pp. 25-34. doi:10.1007/978-0-8176-8238-5_4

[22] P. Kumar and M. Sharan, "An Analytical Model for Dispersion of Pollutants from a Continuous Source in the Atmospheric Boundary Layer," Proceedings of the Royal Society A: Mathematical, Physical and Engineering Sciences, Vol. 466, No. 2144, 2010, pp. 383-406. doi:10.1098/rspa.2009.0394

[23] J. S. Perez Guerrero, L. C. G. Pimentel, J. F. Oliveira Jr., P. F. L. Heilbron Filho and A. G. Ulke, "A Unified Analytical Solution of the Steady-State Atmospheric Diffusion Equation," Atmospheric Environment, Vol. 55, 2012, pp. 201-212. doi:10.1016/j.atmosenv.2012.03.015

[24] A. K. Blackadar, "Turbulence and Diffusion in the Atmosphere: Lectures in Environmental Sciences," SpringerVerlag, Berlin, 1997, 185p. doi:10.1007/978-3-642-60481-2

[25] M. T. Vilhena, D. Buske, G. A. Degrazia and R. S. Quadros, "An Analytical Model with Temporal Variable Eddy Diffusivity Applied to Contaminant Dispersion in the Atmospheric Boundary Layer," Physica A: Statistical Mechanics and Its Applications, Vol. 391, No. 8, 2012, pp. 2576-2584. doi:10.1016/j.physa.2011.11.001

[26] S. E. Gryning and E. Lyck, "Atmospheric Dispersion from Elevated Source in an Urban Area: Comparison between Tracer Experiments and Model Calculations," Journal of Climate and Applied Meteorology, Vol. 23, No. 4, 1984, pp. 651-654.

[27] M. L. Barad, "Project Prairie Grass: A Field Program in Diffusion," Geophysical Research Paper No. 59, Vols. I and II, AFCRL-TR-58-235 (ASTIA Document No. AF152572), Air Force Cambridge Research Laboratories, Bedford, 1958.

[28] F. T. M. Nieuwstadt, "An Analytical Solution of the Time-Dependent, One-Dimensional Diffusion Equation in the Atmospheric Boundary Layer," Atmospheric Environment, Vol. 14, No. 12, 1980, pp. 1361-1364. doi:10.1016/0004-6981(80)90154-7

[29] J. C. Doran and T. W. Horst, "An Evaluation of Gaussian Plume-Depletion Models with Dual-Tracer Field Measurements," Atmospheric Environment, Vol. 19, No. 6, 1985, pp. 939-951. doi:10.1016/0004-6981(85)90239-2

[30] G. A. Degrazia, H. F. Campos Velho and J. C. Carvalho, "Nonlocal Exchange Coefficients for the Convective Boundary Layer Derived from Spectral Properties," Contributions to Atmospheric Physics, Vol. 70, No. 1, 1997, pp. 57-64.

[31] G. A. Degrazia, D. Anfossi, J. C. Carvalho, C. Mangia, T. Tirabassi and H. F. Campos Velho, "Turbulence Parameterization for PBL Dispersion Models in All Stability Conditions," Atmospheric Environment, Vol. 34, No. 21, 2000, pp. 3575-3583. doi:10.1016/S1352-2310(00)00116-3

[32] H. A. Panofsky and J. A. Dutton, "Atmospheric Turbulence," John Wiley \& Sons, New York, 1984.

[33] J. S. Irwin, "A Theoretical Variation of the Wind Profile Power-Low Exponent as a Function of Surface Roughness and Stability," Atmospheric Environment, Vol. 13, No. 1, 1979, pp. 191-194. doi:10.1016/0004-6981(79)90260-9

[34] S. R. Hanna, "Confidence Limit for Air Quality Models as Estimated by Bootstrap and Jacknife Resampling Methods," Atmospheric Environment, Vol. 23, No. 6, 1989, pp. 1385-1395. doi:10.1016/0004-6981(89)90161-3 